Box 1: US Environmental Protection Agency guidelines for disposing of broken fluorescent bulbs

- Open a window and leave the room (restrict access) for at least 15 minutes.

- Remove all materials you can without using a vacuum cleaner. Wear disposable rubber gloves if available (do not use your bare hands). Carefully scoop up the fragments and powder with stiff paper or cardboard. Wipe the area clean with a damp paper towel or disposable wet wipe. Sticky tape (e.g., duct tape) can be used to pick up small pieces and powder.

- Place all cleanup materials in a plastic bag and seal it. If your jurisdiction permits you to put used or broken compact fluorescent lamps in the garbage, seal the compact fluorescent lamp in 2 plastic bags and put in the outdoor trash (if no other disposal or recycling options are available). Wash your hands after disposing of the bag.

- The first time you vacuum the area where the bulb was broken, remove the vacuum bag once you have finished cleaning the area (or empty and wipe the canister) and put the bag or vacuum debris, as well as the cleaning materials, in 2 sealed plastic bags in the outdoor trash or a protected outdoor location for normal disposal.

says Veitch. "Your bigger risk, if you broke the lamp, is you'd have a lot of slivers of broken glass around."

Both Veitch and Bullough say the more problematic issue surrounding mercury and compact fluorescent bulbs lies in their disposal. The mercury in bulbs dumped at landfills can leach out into the water supply, be converted into a highly toxic form called methylmercury and work its way back into the food chain. Ideally, the mercury should be recycled, Bullough says. But there are other environmental trade-offs that must to be factored into the long-term equation when considering bulb disposal, he adds. A power plant emits Io milligrams of mercury to produce the electricity needed to run an incandescent bulb, compared with 2.4 milligrams for a compact fluorescent, so the net effect of using fluorescent bulbs is still an overall reduction in environmental mercury.

When compact fluorescent bulbs became widely available in the midI980s, several studies were published suggesting there was an elevated melanoma risk, but those have since been discredited, Veitch adds. "With respect to cancer risk, there is no good evidence that anyone need fear from the use of compact fluorescents or regular fluorescent tubes. There's no risk for melanoma from either of those lamp types."

Bullough says the average person would have to go out of their way to find a special compact fluorescent bulb that emits a large amount of short-wave, ultraviolet radiation and then spend untold hours under the lamp trying to induce sunburn before there would be anything like a risk of skin melanoma. "You'd really have to work at it."

Experts also say that other health effects often anecdotally associated with fluorescent lights, such as headaches, eye strain and depression, are similarly difficult to quantify, scientifically.

Earlier versions of fluorescent bulbs operated at much lower frequencies (I20 Hertz) compared with newer ones (typically, $30000-40000$ Hertz) and used a different ballast (magnetic rather than electronic) to stabilize the current in the circuit, causing some people to perceive a flicker in the lighting and experience headaches or eye strain. But newer bulbs are "way beyond the ability of the nervous system to detect any kind of oscillation in the output," Veitch says.

Still, "it's possible there are subgroups, of which we're not aware, that could be particularly sensitive" to fluorescent lighting, she adds.

Dr. Julia Knight, senior investigator and leader of the Prosserman Center for Health Research at the Samuel Lunenfeld Research Institute associated with the University of Toronto's Mount Sinai Hospital, says there may be similar remote possibilities and uncertainties related to the impact of fluorescent lighting on circadian rhythms and the production of the hormone melatonin. Studies have linked disruption of the melatonin cycle with the growth rate of malignant tumors. Limited evidence suggests the cycle is disrupted by exposure to very bright light from the blue end of the visual spectrum, Knight says. As for the difference between incandescent and fluorescent lighting: "I'm not sure we know enough to be sure, but I'm not concerned about it."

Veitch, a psychologist by training, says that some people will be far more distressed by "aesthetic" effects resulting from a shift to fluorescent, as opposed to incandescent, bulbs. The 2 types are weighted differently towards differing parts of the visual spectrum, so colours will appear slightly different, while the light that is generated will diffuse differently and have a differing "directionality," leading some people to believe that fluorescents are less bright, even though they're emitting the same amount of light.

Yet, even then, there should be no ill-consequence in terms of eye strain, and no impact on activities like reading, Veitch adds. "If there is, then people may want to choose a slightly higher wattage of CFL [compact fluorescent lamp] but even if they do that, they'll still be saving energy." - Wayne Kondro, CMAJ

DOI:I0.1503/cmaj.0708I6

\section{News@ a glance}

Mumps misery: Some 460 confirmed cases of mumps have now been reported in 8 Canadian provinces in the ongoing outbreak of the acute viral infection, according to the Public Health Agency of Canada. As of June 8, the outbreak remains centred in Nova Scotia, where 350 cases have been confirmed, and New Brunswick, where 88 have contracted the disease. Ontario has I 3 confirmed cases, while PEI, Manitoba, Alberta and BC each have 2, and Newfoundland I. The majority of cases continue to occur among university-aged individuals (see editorial, page I2I). 
On the philanthropic war front: Hey, Larry! The Bill and Melinda Gates Foundation donated US\$105 million to the University of Washington to help create an Institute for Health Metrics and Evaluation to analyze and evaluate the relative merits of world health models, programs and spending. World-reknowned health economist Dr. Christopher Murray was promptly raided from the University of Harvard to head the initiative. Murray is none other than the man who was slated to head the once-planned Ellison Institute to assess world health models, programs and spending, until Oracle Corp. founder (and Gates' current philanthropic rival) Larry Ellison rescinded a promised \$II5 million gift to Harvard because of his concerns over the departure of then-president Lawrence Summers.

HIV testing: The World Health Organization and UNAIDS (the joint United Nations Programme on HIV/AIDS) have issued new guidance for HIV testing and counselling within member nations. Rather than client-initiated testing, health care providers are urged to automatically initiate HIV testing and counselling for all patients who attend health facilities in those countries in which there are generalized HIV epidemics, irrespective of whether the patient has symptoms and regardless of his or her reason for attending the facility. In countries in which there are "concentrated or low-level HIV epidemics," testing should be initiated for "all patients in selected health facilities, (e.g. antenatal, tuberculosis, sexual health, and health services for most-at-risk populations)."

Liquor labelling: The British government and alcohol industry have reached a voluntary agreement to place health warning labels on all beer, wine and hard liquor packaging that indicate the number of units of alcohol ( $\mathrm{I}$ unit is $\mathrm{I} / 3$ of an ounce) that each drink contains, as well as recommended "safe" drinking levels, commencing next year. "We want to make it as simple as possible for people to keep an eye on how much they are drinking," said Public Health Minister Caroline Flint.
Serology lab: Global giant GlaxoSmithKline will pump $\$ 50$ million into an upgrade of its Laval, Que., facility, including construction of a serology lab in the vacant basement of the facility and the hiring and equipping of 60 new staff. The move is part of a GlaxoSmithKline plan to designate the Laval facility as the North American headquarters of its innovative vaccines division. The firm has committed itself to developing 5 vaccines by 2010, targeting rotavirus infection, uterine cancer, pneumococcus for babies, the flu for the elderly and meningitis for children under the age of 2 .

The obesity waltz: Concerns about expanding obesity rates have prompted the government of China to make dance classes mandatory for elementary and secondary students, commencing Sept. I. The classes will "suit the physical and psychological characteristics of students at all ages," according to a notice from the Education Ministry, which also considering the adoption of physical fitness as a criteria for entry in the nation's ultracompetitive university system.

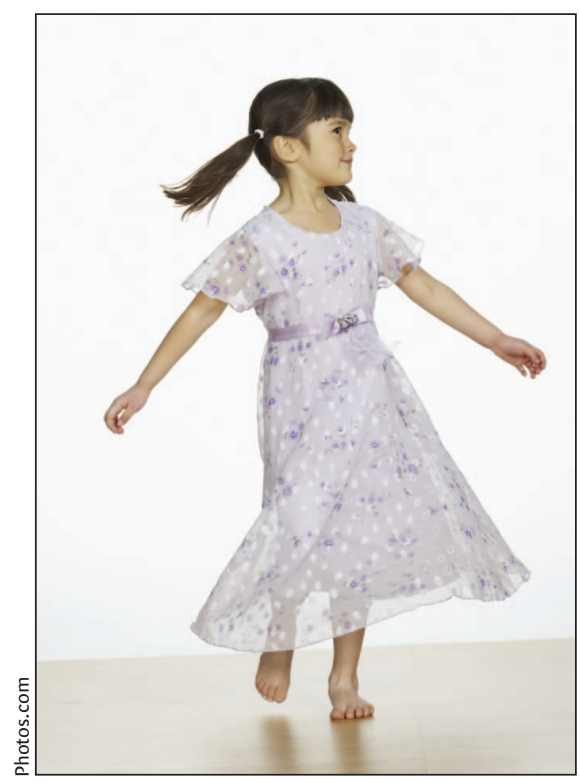

Double-dipping: The Montréal-based medical brokerage firm Medicina opted to shut down its operations after the Régie de l'assurance maladie du Québec ordered it to stop paying medical specialists for offering patients more rapid access to services. The firm had been charging patients $\$ 90-\$ 290$ for appointments with specialists, who, in turn, were typically paid about \$150 for agreeing to see the client. The health insurance board ruled that that contravened the province's public health plan, which prohibits doctors from charging patients for extra costs associated with medical services. Some 15 specialists were caught double-dipping.

Coalition complaint: The Coalition of Associations for Foreign Trained Doctors has asked the Quebec Human Rights Commission to investigate whether immigrant physicians are being systematically discriminated against when applying for hospital residency programs. Roughly 200 immigrant physicians in Quebec passed qualifying exams this year but only 54 were granted residency spots, while 87 available positions weren't filled. A class action suit is also being contemplated.

Wrinkles ironed: An Anglophone medical training program will be established at the University of New Brunswick's Saint John campus. The New Brunswick government has announced that it has now resolved logistical issues surrounding the establishment of 30 undergraduate training spots at the university (CMAJ 2007;176 [10]:I405) .

Lord help us: Ousted New Brunswick Conservative premier Bernard Lord has been named the first "scholar-inresidence" at the newly minted Institute for Strategic Analysis and Innovation, a health care think-tank established at the McGill University Health Centre in Montréal. Lord has been charged with crafting strategic policy plans "focusing on equipping citizens to take control of their own health care management."

Burden of proof: Although studies have found no causal link between autism and childhood vaccines containing thimerosal, the parents of a I2-year-old Arizona girl have asked the US Court of Federal Claims to find that their child's autism was caused by a measles vaccine. A finding in 
their favour would make the family eligible for monies from the US Vaccine Compensation Fund, which was created to safeguard manufacturers from lawsuits while ensuring adequate vaccine supply. The burden of proof in the Court of Federal Claims is lower, requiring only that plaintiffs prove that an association is "more likely than not, based on a preponderance of evidence."

Hip surgery: Senior citizens who have broken hips and are forced to wait longer than I day in hospital for surgery are $22 \%$ more likely to die than those treated within a day of admission, according to a Canadian Institute for Health Information study. The higher death rate is typically the product of complications such as urinary tract infections or pneumonia resulting from being immobilized and bedridden. There was also a significant variation in the rapidity of treatment relative to size of the hospital. Some $74 \%$ of patients admitted to small hospitals received same or next day surgery, compared with $67 \%$ in medium and large community hospitals, and $57 \%$ in teaching hospitals. The study, which indicated that 25000 seniors were admitted to hospital because of a broken hip in 2006, is available at www.cihi.ca

Foreign credentials: The federal government has unveiled the first phase of its newly minted Foreign Credentials Referral Office, a \$32.2 million, 5 -year initiative created in the 2007 federal budget to help International Medical Graduates and other foreigntrained professionals get readier recognition of their credentials. In addition to online information about potential occupations and job opportunities, the new office will provide immigrants with a dedicated phone service at 320 Service Canada outlets by this fall. - Wayne Kondro, CMAJ

DOI:I0.1503/cmaj.070817

\section{DISPATCH}

\section{Canadian dispatches from medical fronts: Whaling}

$\mathrm{T}$ he sun rose slowly as I picked up the pacemaker programmer at my Yellowknife clinic, headed to the airport, and flew north into darkness. As I landed in Inuvik - north of the Arctic Circle - it rose a second time, even more reluctantly. The pacemaker machine and I shared a taxi to the local hospital, where I began a 4-day internal medicine travel clinic.

On Tuesday morning, I saw patients who had flown into Inuvik from the village of Aklavik. Seventy-five-year-old Sarah stumped cheerfully into the examining room, sporting a magnificent parka and trailed by her sister Naomi. They wore matching mukluks of wolf fur - apparently originating from the same animal, and beautifully decorated by hand. "Used to keep wolf warm — now me!" chuckled Sarah. Both weathered Inuit faces were framed in wolverine and wolf furs - the "sunburst" hoods that often adorn calico parkas in the high Arctic.

Sarah stripped off 3 or 4 layers, and I hooked up the machine to check her pacemaker. The battery was getting low and she was entirely pacemaker dependent. I checked the thresholds, reprogrammed a couple of parameters, and noted the absence of underlying rhythm while she chatted to her sister. Then I noticed from her chart that she had missed her last appointment. I tried to summon a frown as I unhooked the leads and mentioned the no-show to Sarah.

"Oh yes, in the summer. Nurse told me to go see doctor in Inuvik. I said, 'No! I'm going whaling!' We had really good season at whaling camp, doctor. Lots of good muktuk this year." Her sister nodded, smiled and raised her eyebrows in agreement. Evidently she enjoyed whaling as well.

"But Sarah, your battery is getting low and your pacemaker could stop working if you miss your appointments to have it checked."

"Oh, I won't miss again! I'll be good this time doctor, I promise - whaling camp is only once a year."

She was penitent, but still playful as she donned her parka again. She didn't mind coming to Inuvik in November, when she could replenish her sewing supplies and buy Christmas presents for her family. Both sisters shook my hand, smiled broadly and wished me a happy Christmas as they headed out into the mid-day twilight.

I sighed - at my fondness for Sarah, at my weak attempt to play tough with a wise woman who sets her own priorities.

She was doing her best to cooperate with the young lady doctor from down south (i.e., Yellowknife). I decided I could work around the whales. Amy Hendricks MDCM, Yellowknife, NWT

CMAJ invites contributions to "Canadian dispatches from medical fronts," in which physicians and other health care providers can provide eyewitness glimpses of the medical front, whether defined by location or intervention. Without intending to restrict options, the front can be defined as any unique confluence of time and event, whether in developing countries, war zones, inner-city clinics, in the North, or with a novel surgical technique or intervention. The frequency of the section will be conditional on submissions, which must run a maximum 350 words or be subject to our ruthless editorial pencils. Forward submissions to: Wayne.Kondro@cma.ca

DOI:I0.I503/cmaj.070822 